\title{
Chapter 22 \\ Understanding and Defending the Preference for Native Species
}

\author{
Ned Hettinger
}

\begin{abstract}
The preference for native species, along with its concomitant antipathy toward non-natives, has been increasingly criticized as incoherent, obsolete, xenophobic, misanthropic, uncompassionate, and antithetical to conservation. This essay explores these criticisms. It articulates an ecological conception of nativeness that distinguishes non-native species both from human-introduced and from invasive species. It supports, for the most part, the criticisms that non-natives threaten biodiversity, homogenize ecological assemblages, and further humanize the planet. While prejudicial dislike of the foreign is a human failing that feeds the preference for natives, opposition to non-natives can be based on laudatory desires to protect natural dimensions of the biological world and to prevent biological impoverishment. Implications for our treatment of non-native, sentient animals are explored, as well as are questions about how to apply the native/non-native distinction to animals that share human habitats and to species affected by climate change.
\end{abstract}

Nature doesn't care about conservationists' artificial divide between...native and alien species...The concept of natural has outlived its usefulness in conservation...Aliens are rapidly changing from being part of the problem to part of the solution. (Pearce 2015b)

Their demonization says more about us and our fears of change than about them and their behavior...This hostility is generally justified by outdated and ill-founded ideas about how nature works... We need to lose our dread of the alien and the novel...Conservationists must stop spending all their time backing loser species-the endangered and the reclusive. They must start backing some winners. (Pearce 2015a, xii-xvi)

Biological invasions are fundamentally analogous to natural disasters...the annual combined economic cost of invasions worldwide exceeds that of natural disasters. (Ricciardi et al. 2011, 312)

\footnotetext{
N. Hettinger $(\bowtie)$

College of Charleston, Charleston, SC, USA

e-mail: HettingerN@cofc.edu
} 


\subsection{Introduction}

I once planted a Mimosa tree in my yard on a barrier island off the coast of the U.S. state of South Carolina. I'd seen the trees around the island and thought their gorgeous, showy pink flowers would make a good addition to our palms, live oaks, cedars and wax myrtles. When I learned that Mimosa was a species from east Asia, I was upset. I wanted our yard to fit in with the native ecosystems of barrier islands off the Southeast U.S. coast. I believed that planting "alien" or "exotic" species was incompatible with the integrity of our island native ecosystem. While it was true that may Mimosas, as well as other non-natives species, inhabited our island, I did not want to be a part of what I considered a degradation. It was like planting California redwoods in Northern Europe or transporting Camels into the U.S. southwestern desert: These species did not belong in those places.

Although the idea that non-natives should be kept out of native ecosystems is strongly endorsed by most environmentalists, over the last twenty years it has been subject to increasing criticism. "Nativists" (those with a preference for native species and an antipathy toward non-natives) are accused of xenophobia, not only for having an irrational fear of and hostility toward alien species, but also for being complicit with the recent and growing prejudice against human immigrants. Nativists are also accused of being in the grip of a scientifically uniformed conception of natural systems, mistakenly believing that they are unchanging, tightly knit communities whose species composition remains fixed. It is argued that in a time when human alteration and domination of the natural world is extensive and ever increasing ("the Anthropocene"), with consequent loss of endemic species and collapsing ecosystems, we need to embrace non-natives and the novel ecosystems they create. Such ecological novelty is a positive contribution to the only nature that we can hope of sustaining on earth. Rather than treating non-native species as a plague to be eradicated (as when the U.S. National Park Service shoots Mountain Goats that have strayed into the parks), non-native species should be seen as a part of nature and part of the biodiversity we should be preserving.

Some scientists have even suggested that the discipline that studies non-native species (invasion biology) constitutes a "pseudoscience" (Theodoropoulos 2003) and should be dissolved. Critics within the field have worried about its use of misleading war-like metaphors and claimed that it often misrepresents the behavior of colonizing species, which are far more benign than they are made out to be (Davis et al. 2011). They argue against "judging species by their origin" and against the presumption of guilt, insisting instead that non-natives should be treated as innocent until proven otherwise. In response, some invasion biologists accuse the supporters of this more open attitude toward non-natives of engaging in "science-denialism," analogous to those who deny the reality of climate change, arguing that the threat non-natives pose is undeniable (Russell and Blackburn 2017).

This essay defends the preference for natives over non-natives. While the critics raise a number of important issues that a defender of native species must accommodate, their criticisms can, by and large, be successfully addressed. A precising 
definition of nativeness will be offered along with a defense of respect for independence nature, a nature threatened by the vast spread of human-introduced non-natives. Further, while non-natives add to biodiversity in some ways, in more important ways, and overall, they lessen it. And while a welcoming and cosmopolitan approach to the foreign has its virtues, so too does promoting traditional communities and unique ways of life. Non-natives and novel ecosystems have a place in this increasingly humanized world, but, more importantly, so too do natives and traditional ecosystems.

\subsection{The Distinction Between Native and Non-Native Species}

There is no agreed upon understanding of what makes a species native or not. Some think the distinction and related concepts are hopelessly muddled, deceptive, and should be given up (Chew and Hamilton 2011). One analysis argues that, "Without an explicit criterion, exotic and native are problematically imprecise concepts and are, consequently, often used inconsistently by ecologists and conservation biologists" (Justus 2009, 413). Frequently it is claimed that designating a species as non-native ("exotic" or "alien") is used to manipulate public support for its removal. In an era of anthropogenic global change, some noted scientists think:

It is time for scientists, land managers and policy-makers to ditch this preoccupation with the native-alien dichotomy and embrace more dynamic and pragmatic approaches to the conservation and management of species - approaches better suited to our fast-changing planet. (Davis et al. 2011, 153)

In one of the first careful philosophical treatments of the topic, Woods and Moriarty (2001) distinguish five possible accounts of what it means to be a native species: The human introduced criterion, the evolutionary origin criterion, the historical range criterion, the degradation criterion, and the community membership criterion. They argued that no one of these was correct and instead that we should think of the idea of native species as a "cluster concept." In their view, none of these features is either necessary or sufficient for being native, but the more of them a species possesses, the more likely they should be considered native. Correlatively, they argue, the less a species instantiates these features, the more likely it is non-native.

The most common idea is that what makes a species non-native is that it was introduced to an ecosystem by humans. The Netherlands' Minister of Agriculture has defined native species thus:

I define an exotic species as a non-native plant, animal or micro-organism that is not able to enter the Netherlands by its own efforts, but through human activity (transport, infrastructure) and has entered nature in the Netherlands, or threatens to do so in the near future. Species that enter the Netherlands by their own efforts, due to climate change for instance, fall outside this definition and are not included in the policy. (Verburg 2007)

Such a definition will not do. On the one hand, this account ignores that species can and do travel to new and radically different habitats on their own, as when ballooning 
spiders arrive on remote oceanic islands or vagrant birds get blow from one continent to another. For example, when Cattle Egrets first arrived in South America having been carried by winds from Africa, it was not plausible to think of them as native there. On the other hand, the human-introduced criterion fails to allow for the possibility of human restoration of native species, as was done with the 1990s restoration of wolves to Yellowstone National Park in the U.S. Wolves had been in the Park until they were eradicated in the early 1920s. Seventy years later the Park Service transported wolves from Canada back into Yellowstone. On the human-introduced criterion, it would make no difference whether the park had trucked in wolves from Canada or flown in Siberian snow leopards from Russia, both were brought there by humans and would thus be non-native.

An almost equally popular (and problematic) idea of non-native species is that they are species that "invade" and wreak havoc in local ecosystems. In fact, "non-native species" and "invasive species" are often used interchangeably. Such species come in and take over an ecosystem causing massive amounts of damage, often extirpating local endemic species. An often-cited example are the introduction of cane toads to Australia. In 1935, hoping South American Cane Toads would control the beetles that were plaguing their sugar cane crop, farmers brought in about a hundred. The toads spread quickly, and today, they exist "from coast to coast," sometimes in densities of a thousand an acre. There are now an estimated 1.5 billion of these toxic critters in Australia poisoning native animals who eat them (Crawford 2018; Slezak 2015). Another often cited example is Kudzu (Pueraria lobata) in the U.S. A Japanese vine imported in the early 1900s and planted to reduce soil erosion, it has a growth rate of up to a foot a day, spreads over 200 square miles (518 sq. $\mathrm{km}$ ) a year, and now covers millions of acres in the southeastern United States, killing trees and shrubs by heavy shading. Or consider that European zebra mussels, arriving into the U.S. Great Lakes in ship ballast water, clog water intake pipes at a cost of hundreds of millions of dollars annually. ${ }^{1}$

While it is undeniable that some non-native species have devastating consequences both for nature and for humans, it is a mistake to equate non-natives with damaging invasives. For the most part, non-natives do not cause problems, either because they quickly die out or, if they do establish a permanent presence, they do not aggressively spread and cause problems. While not scientifically rigorous, a ballpark estimate is the often cited "tens-rule" that claims one in ten introduced non-natives survives in the wild and that only one in ten of these goes on to spread problematically.

Not only are many non-natives ecologically benign, but native species also can irrupt and cause massive damage. While "invasive" suggests entering from outside, it also can mean encroaching or infringing, and aggressively spreading from within can also count as "invasive" in this sense. For example, the native pine beetle in the U.S. "is currently suspected to be killing more trees than any other [insect] in North

\footnotetext{
${ }^{1}$ Why are such non-natives so successful? The science behind this success is not settled, but some of the factors often mentioned are that the parasites, predators, and competitors that keep these species in check in their native habitats are not present in their new home and that their new neighbors (unlike their neighbors back home) have not developed defenses against them.
} 
America" (Davis et al. 2011, 153). One study titled "The natives are restless, but not often and mostly when disturbed" (Simberloff et al. 2012) suggest that while native species do sometimes spread dramatically, they do so less frequently than non-native species and most often the irruption is the result of human-caused changes (such as grazing pressure or fire suppression). So, non-natives cannot be equated with damaging invasive species.

Nor should we can we think of natives as those that originally evolved in a location and non-natives as those that originally evolved someplace else. For species routinely move around and colonize new areas where they make their home for thousands of years and thus are clearly native. Such a criterion would implausibly entail that longlived colonizers on volcanic islands are non-natives while species that just recently evolved in that local are native. Or consider a species that evolved in one locale and then migrated to other places, while dying out in its original location. The story of Camel migration is instructive. The ancestor of the modern camel species evolved in North America and then spread to South America and Asia. Camels went extinct in North America when humans migrated to the continent thousands of years ago. Depending on how strictly we use the term "species" (species per se or closely related taxon), the evolutionary origin criterion would suggest that returning Camels to North America would be restoration of a native species. The idea that a herd of Camels roaming the American Southwest should be considered native species to those ecosystems is on its face preposterous!

I suggest that we think of native species as species that have considerably interacted/adapted to the local biota and abiota. Natives are tied to other residents via some sort of interaction, whether competition (such as predation) or cooperation (such as mutualism). Natives have influenced other natives and adapted to local climate and landscape. Similarly, the locals have interacted with and adapted with them. Perhaps the local abiota have been affected by their presence as well. So native species are those that have significantly adapted to or interacted with the local biota and abiota (and vice versa). Non-natives are species that have not significantly adapted or interacted with the local inhabitants or abiota. ${ }^{2}$

This notion of having significantly adapted or interacted with locals is not the same as fitting in functionally (that is, performing certain ecological functions). A species that has never actually adapted to local species might fit in fine, but is not native. For example, Snow Leopards in Yellowstone might serve the same roles as wolves, but they are non-natives as they have not actually adapted with local species. Note too that this conception of native species does not assume some ideal balance of nature or harmony in ecosystems. Natives are those that have interacted and adapted to each other; whether that interaction is harmonious or not, in balance or not, is left open.

This conception of the native/non-native distinction is ecological and not geographical. For example, the idea of a species being "native to North America" makes no sense on my account. There are too many different ecological assemblages for a species to have interacted and adapted with all of them. Nor is it helpful to think

${ }^{2}$ I first proposed this idea in Hettinger (2001). 
of species as native to a state or region, unless such geographical designations are uniform in terms of their ecology. ${ }^{3}$ On this account of native species, "native to a place" makes no sense, unless place means ecosystem.

Note also that on this conception being native or not is a matter of degree. Obviously, the extent to which a species has significantly adapted/interacted can increase (or decrease) over time. This allows that a species that comes into a foreign habitat can "naturalize" over time as it interacts with the locals and they interact with it." Camels that evolved in North American ecosystems 50 million years ago and then moved to Asia via the Bering land bridge presumably became native in the new desert ecosystems they inhabited for millions of years. Given uncertainty in biological taxonomy and the looseness in the use of the concept of species-including whether we are talking about members of the same sub-species, the same species, or perhaps even the same genus-whether or not organisms are "native species" would also seem to admit of degrees for that reason. For example, what if the wolves used to restore the Yellowstone population had been from a region of Alaska with somewhat different habitat than what existed just north of the Montana-Canadian border where the restored wolves were captured? Or what if the restored wolves had a greater percentage of red wolf, coyote, or even African Golden wolf (a jackal) genes that those that previously resided there? Presumably in these cases the restored wolves would be somewhat less native. Or consider that polar bears and grizzly bears have increased their interbreeding due to climate change. If such a hybrid was either transported to or found its way into Yellowstone, it seems reasonable to say it is "somewhat native" to the Park. Additionally, because the boundaries of ecological assemblages or ecosystems are also not always clear, whether a species is native or not, and to what extent, depends of how one understands the boundaries of the ecosystem it is in.

Recognizing that nativeness is a degree phenomenon helps us see that climate change, while problematic for the concept, need not undermine it, as many seem to think. It will, of course, put additional pressure on native species and increase the relative abundance of non-natives. How much nativeness will survive depends on how dramatically climates change and in what ways. In general, climate change will lessen the degree of nativity of stationary natives as they become less adapted to local abiotic conditions (such as temperature and moisture). Such species will also become less adapted to the local biota insofar as ecosystems "reshuffle":

New climates are expected to cause ecosystem reshuffling as individual species, constrained by different environmental factors, respond differently. One tree may be limited by summer rains that hold back seedling recruitment, for instance, whereas another species may be limited by winter freezes that control insect pests. Some species may migrate up-latitude or

\footnotetext{
${ }^{3}$ Perhaps some generalist species are counterexamples. For example, coyotes now inhabit much of North America (though not the arctic regions). European starlings are another similar example.

${ }^{4}$ Note that I am not using "naturalized" identically to the usual biological understanding according to which any non-native that establishes a self-sustaining community of individuals in a new habitat has naturalized. Note further that the possibility of naturalization over time implies that novel ecosystems (human-caused but not maintained ecosystems with unique combinations of species or functions) might eventually be composed of thoroughly native species.
} 
up-elevation, while others stay put. An ecosystem might see many species vanish—but also new arrivals. (Fox 2007, 823)

Some native animals and plants will no longer be able to survive in their historical habitats and so will either have to move or die out. In so far as ecological assemblages shift en masse, say migrating north as the temperature rises, their component species will remain (relatively) native. But if "reshuffling," rather than mass migration, is the norm, nativeness of species will dramatically decline and many native species will become non-natives, either in their original location as their neighbors and abiota have changed, or in their new location, as they join species to which they have not adapted/interacted. "As climate change pushes more species out of their home ranges and into new areas, the number of so-called invaders is likely to multiply exponentially" (Goode 2016). There remains the possibility of naturalization over time when and if the ecological disruptions climate change causes cease.

This account of the native/non-native distinction has some intriguing implications for conservation policies. For example, assisted migration of endangered species need not be exotic introduction. Species moving from an historical range can remain native if they have sufficiently adapted to species in the new location. Thus, assisted migration would count as native introduction when the species and abiota in the new site are sufficiently similar to the species and abiota extant in the previous location. Or consider the use of genetic engineering to increase the fitness of a species. For example, to protect American pica from an increasing warm climate, we might introduce foreign genes from more heat adapted populations or species into the endangered pica populations. These altered picas would be more or less native depending on the extent of their alteration. ${ }^{5}$ The preference for native species would entail using genes from the most closely related populations, sup-species, or species.

This account also sheds light on how we might think about Pleistocene rewilding and de-extinction. There have been recent discussions about the existence of "ecological anachronisms," that is, extant species adapted to extinct species. For example, it is argued that the speed of antelope in the American West (over $60 \mathrm{mph} / 95 \mathrm{kmh}$ !) evolved and was an adaptation to cheetah like predators who long ago went extinct in America. If many species today are still adapted to extinct species, then bringing those species back (say by cloning using ancient DNA) and locating them with many of their co-evolved species could count as return of natives or at least "somewhat native species." Attempts at back breeding to mimic extinct species might also produce somewhat native species, depending on how similar those species are to the extinct type and how similar the extant habitat is to what once existed.

While the degree phenomenon of nativeness means there are not sharp lines to be drawn and that borderline cases will have to be confronted, especially with the advent of climate change, at the extremes there are innumerable clear cases of native and non-natives on this account. Additionally, the preference for native species over non-natives remains useful even in cases where the distinction is not clear cut.

\footnotetext{
${ }^{5}$ See Palmer (2016) for a useful discussion.
} 


\subsection{The Prevalence of Non-Native Species}

The assumption among environmentalists and others who prefer native species and harbor an antipathy towards non-natives is that non-natives represent disvalues of various sorts. To assess these value judgments, we need first to address some factual questions concerning non-natives. As it turns out, getting clear on the facts about non-natives is not straightforward for there is considerable scientific controversy concerning them.

How pervasive are non-natives? The numbers vary widely. The U.S. Fish and Wildlife service, citing a 2005 study by Pimentel et al., suggests there might be 50,000 non-native species in the U.S. Citing a 1999 study, it estimates that about $10 \%$ of them are invasive. Elizabeth Kolbert reports that "California alone acquires a new invasive species every sixty days" (Kolbert 2014, 211). The Global Invasive Species database lists 149 invasive species in the Netherlands (and 498 in the U.S.). A recent study of recorded "established" alien species comes up with about 17,000 worldwide and ominously concludes that:

For all taxonomic groups, the increase in numbers of alien species does not show any sign of saturation and most taxa even show increases in the rate of first records over time. This highlights that past efforts to mitigate invasions have not been effective enough to keep up with increasing globalization. (Seebens et al. 2017, 1)

Climate change will undoubtedly increase the number of non-natives, perhaps exponentially. Given that we do not have a fixed idea on the total number of species on earth (estimates range from 3 million to 100 million to even a trillion-only 1.7 million have been described) the relative presence of non-native species compared to natives also cannot be determined. What we do know is that in some places they are very widespread. One study of central European cities found that $40 \%$ of plant species were alien (Pysek 1998). Another study suggests that "non-native plants and birds can make up $50 \%$ or more of species in some urban, insular, and old field environments" (Schlaepfer 2018).

While species invasion is an ancient and natural phenomenon essential for the flourishing of live on earth, recent human-caused introduction of non-natives is dramatically different, moving species far more rapidly and across greater distances and barriers:

\footnotetext{
The human-induced rate not only of species extinction but also of species invasion has increased exponentially, in concert with the exponential growth of the human population over the last few hundred years. In addition, in more recent decades, global human travel and commerce have increased disproportionately relative to the increase in the sheer number of humans. Combined, these actors have produced burgeoning rates of nonindigenous species in every ecosystem that has been monitored...Although species invasions are natural, both the rate of their occurrence and the distances traversed by species now exceed by orders of magnitude those of only a few hundred years ago. (Lodge and Shrader-Frechette 2003)
}

In short, non-native species are pervasive in many ecosystems and humanintroduction of non-natives continues at an unnatural and potentially alarming rate. 


\subsection{Judging Species by Their Origin}

Should we be worried about this dramatic rise of the non-native? Many environmentalists are deeply alarmed. But an increasingly accepted idea is that the generalized negative attitude toward non-natives is prejudicial. An influential article in the prestigious science journal Nature proclaimed that we "ought not to judge species on their origin" (Davis et al. 2011). These critics suggest that the antipathy toward exotics involves the problematic (and even xenophobic) attitude of assuming that what hails from elsewhere is inherently bad. They think of the widespread efforts to control or remove non-natives as "persecution of the new just because it is new" and question "why our default attitude to novel biodiversity is antagonism or ambivalence" (Thomas 2013). One prominent invasion biologist suggests "the dominant paradigm in the field is still a 'when in doubt, kill them' sort of attitude" (Goode 2016).

Perhaps we should not be alarmed by non-natives if they behaved no differently than natives. But the evidence is that non-natives tend to be more ecologically disruptive than natives. While natives can irrupt and cause ecological upheaval, they do so less frequently than do non-natives. Non-native species are far more likely to have ecological and socio-economic impacts than do those native species that, for various reasons, undergo range expansions or increase in abundance to become 'weedy' (Simberloff et al. 2012). One study documents that non-native predators and herbivores had about $2 \frac{1}{2}$ times the impact on native prey than did native consumers (Paolucci et al. 2013), results that fit the common sense idea that native species will learn how to handle their native predators better than those with whom they have not interacted. Therefore:

Ignoring biogeographic origins as a mediator of impact ignores the importance of evolutionary context in species interactions...The more 'alien' an established animal, plant or microbe is to its recipient community, the greater the likelihood it will be ecologically disruptive. (Richardson and Ricciardi 2013, 1463)

The defenders of non-natives can respond that "ecological disruption" is not necessarily a problem, or if the disruption is negative, how harmful these impacts are is open to question. They will argue that rather than assume a non-native will be problematic, that is, rather than approach non-natives as "guilty unless proven innocent," we should assess them individually in terms of their benefits and costs. Even though non-natives are more likely to cause disruption than natives, to assume that they will be disruptive (without specific evidence that they will be-other than their "alien" status), would only make sense if this likelihood was quite high. Given the "tens rule" it is not at all clear that it is.

Consider an analogy with human immigrants. Assume it true that a new immigrant to a country is more likely to be disruptive (e.g., culturally) than a citizen. It would only make sense to presume guilt (or to justify caution/skepticism) if this likelihood was extremely high or if the possible disruptive behavior was severely harmful. For example, even if immigrants present a greater risk of terrorism than do citizens, unless this risk was high or its possible consequences major (e.g., smuggling in nuclear bombs), it would not be acceptable to assume they will be problematic. So 
the ecological fact that non-natives are more likely to cause ecological disruption than natives does not, w/o further evidence, justify the "prejudicial" precautionary approach to aliens represented by the antipathy many environmentalists have toward them. Below I provide a rationale which I think does justify such a negative attitude, w/o specific evidence of potential for disruptive behavior.

\subsection{Do Non-Natives Threaten Biodiversity?}

A major reason behind the opposition to non-natives is the belief that they are a major threat to biodiversity. If it is true, as has been claimed by numerous published reports over the last 20 years or so, that non-native species are the second leading cause of species extinction world-wide, that would seem sufficient to justify the antipathy toward non-natives, especially given that humans are causing a mass extinction event on a scale not seen on the planet for 50 million years.

Whether, and to what extent, non-native species are a threat to biodiversity is a surprisingly complicated and debated topic. While repeated numerous times in scientific papers, environmental magazines, and news reports, the claim that nonnative species are the second leading cause of extinction (behind habitat destruction) has been discredited and even ridiculed ("a canard," Davis and Chew 2017 call it). It is alleged to be based on shoddy science involving confirmation bias on the part of both committed conservation biologists and ideological environmentalists. Matthew Chew writes:

While carefully recounting the origin, promotion, and deployment of the 'second greatest
threat', I argue that its uncritical acceptance exemplifies confirmation bias in scientific advo-
cacy: an overextended claim reflexively embraced by conservation practitioners and lay
environmentalists because it apparently corroborated one particular, widely shared dismay
about modern society's regrettable effects on nature. (Chew 2015, 1)

First asserted by E. O. Wilson in the 1990s and then rebutted by Mark Davis and 18 colleagues in their 2011 Nature paper, recent studies continue to document it. A 2016 study examined:

The prevalence of alien species as a driver of recent extinctions in five major taxa (plants, amphibians, reptiles, birds and mammals)...Alien species are the second most common threat associated with species that have gone completely extinct from these taxa since AD 1500 ...Aliens are the most common threat associated with extinctions in three of the five taxa analyzed, and for vertebrate extinctions overall. (Bellard et al. 2016)

Mark Davis, who is a well-regarded invasion biologist, continues to dispute this claim by arguing that most of the extinctions documented have taken place on islands where species are far more vulnerable to non-natives than in other places. We cannot generalize these data to the extinction threats on land or in the seas, he suggests, because these biotas are far more resistant to competitive pressure.

A focus on species extinction alone, however, is a limited measure of the loss of biodiversity, for individual members of species can radically diminish in numbers, 
subspecies and populations can be extirpated, and genetic diversity within a species diminished, while the species itself continues to survive. For example, polar bears have not gone extinct as a species, but their numbers and diversity have seriously declined. This point, while important, must be treated with caution. For we cannot simply assume that the loss of individual members of a native species is an overall loss in biodiversity if they are being replaced with non-native individuals-unless, of course, we assume that the biodiversity provided by native individuals is more valuable than that provided by non-native ones. But this begs the question about the superiority of native species over non-native ones.

This point is made all the more poignant by the surprisingly diverse and multiple ways non-natives add to or promote biodiversity. For example, Britain has gained almost 2000 non-native species "without losing anything to the invaders" (Thomas 2013). The same paper reports that, because of hybridization (which can lead to new species), non-natives added to Britain have increased the global species count. Thomas goes on to suggest that warming temperatures resulting from climate change will increase regional diversity because warm-adapted species will invade more quickly than cold-adapted species move out.

Paradoxically (given the severe biodiversity loss attributed to non-natives arriving on the continent), Australia provides another example of how non-natives can add to biodiversity in certain dimensions. The continent lost all of its large (over 200 lbs.) megafauna by the end of the Pleistocene. Now it is home to eight introduced megafaunas, including the only wild population of dromedary camels in the world (Lundgren et al. 2018). In general, 1/3 of very large herbivorous species have wild populations outside their native ranges. While this study focuses on only a small group of species, namely giant herbivores, it is of interest that "the introduced herbivorous giant megafauna of the world have restored species richness across many continents to levels approaching the Pleistocene" (Lundgren et al. 2018, 865). Thus, if we only worry about endangered species in their native habitats, we will miss opportunities for preserving species more widely. Of course, the focus of preserving endangered species should be on preserving them in their native habitats. That they can survive in zoos or as introduced, non-native species in other habitats is of significantly diminished value.

Nevertheless, there are many examples of species endangered at home that are doing well as introduced species in non-native habitats. In some cases, endangered species are even considered invasive. The Monterey pine is endangered in California and Mexico but is treated as a pest in Australia, and Barbary sheep, which are endangered in Morocco, are allegedly overrunning the Canary Islands (Goode 2016).

We clearly should withhold a negative appraisal of non-native species that are also endangered if our objection to non-natives is based on concerns about biodiversity. As argued in an intriguing paper comparing human migrant ethics to the ethics of non-native species, just as refugees (who are endangered in their home countries) are accorded special status among immigrants, so endangered species should be treated as a special class of non-natives (Switzer and Angeli 2016). One scientist argues that the phenomenon of non-native but endangered species is widespread enough that if non-natives were included in biodiversity indices (which they are not now, but which 
he insists they should be), it would lower the extinction predictions for some species (Schlaepfer 2018).

Besides being endangered species in some cases, non-natives have been documented to provide numerous benefits for native species, including rare ones. In California, non-native eucalyptus trees provide habitat for Monarch butterflies. In Spain, non-native crayfish provide food for wetland birds, including some endangered ones (Goode 2016). A striking example is introduced, non-native donkeys in the Sonora desert of the Southwestern U.S. Where water is close to surface, they dig wells used by up to 30 species (including trees). The scientists documenting this phenomenon, argue that the non-native donkeys are increasing the functionality of these ecosystems and their resilience in the face of climate change (Lundgren et al. 2018).

Many point out the obvious fact that the introduction of a non-native species increases the local species count (by one!) (Sagoff 2000). If the number of nonnatives species arriving outnumber the extinctions taking place, species richness will increase. In fact, because of the spread of non-natives, a general trend worldwide is that often local biodiversity (measured by a species count) is increasing even while overall global species numbers are in decline. "Empirical evidence points to ecological increases in the number of terrestrial species in most of the world's regions over recent decades and centuries, even though the total number of species on the planet is declining" (Thomas 2013). A study in the early 2000s of plants and birds on oceanic islands found that land birds species numbers remained constant (despite many extinctions) while plant species numbers doubled. Because those introduced plants and birds existed in other places, there was not global increase in species (Sax et al. 2002).

What are we to make of this tendency? At least in terms of biodiversity, increases in local biodiversity are valuable (unless we discount the biodiversity added by nonnatives!). But if endemic species (those found only in one place) are being replaced with more cosmopolitan species, then the local gain in biodiversity is at the expense of overall global diversity. It seems clear that this is an overall loss in biodiversity. Consider an analogy with human cultural diversity. European humans arrive on an island with several distinct indigenous populations and promptly drive all but one extinct (perhaps they inadvertently infect the locals with diseases never before seen on the island). If enough different nationalities of Europeans arrive, the local diversity of cultures will have increased overall. But we should not count this as an overall increase in cultural diversity, even though there is now greater cultural diversity on this island. ${ }^{6}$ Here is a description of the loss when non-natives replace local endemics:

Native species have coevolved with one another and the physical environment, often resulting in intricate coadaptations. Loss of native species can erase unique evolutionary histories. Therefore, non-native species additions do not compensate for phylogenetic losses resulting from extinctions even if they increase overall local species diversity, because many non-native species erode diversity through local and global extinctions. Even if one is willing to offset the current losses of biodiversity with the promise of new biodiversity as non-native species

\footnotetext{
${ }^{6}$ This fictitious example may actually fairly well represent what happened in North America with the arrival of Europeans.
} 
evolve and diverge, millions of years of biological adaptation and evolutionary history would be lost. (Pauchard et al. 2018, 2)

While the situation is complicated, the overall threat to biodiversity due to nonnative species is real and, in my judgment, significant. Citing the World Wildlife Fund's 2014 living planet index report, Davis and Chew (2017) claim, "More recent assessments of biodiversity effects demote invasive species to a subsidiary role". That study put "invasive species/genes" as the primary threat in $5.1 \%$ of the populations studied, while climate change was primary in $7.1 \%$ of populations (WWF 2014, 20). The 2018 WWF report lists invasive species/disease as again close to climate change in the threat it poses to biodiversity (and for some taxa, a greater threat) (WWF 2018, 72). While true that compared to habitat degradation and direct exploitation, non-native species play a "subsidiary role" in biodiversity loss, the negative effect on biodiversity is close to the threat to biodiversity posed by climate change, and it should not be ignored.

\subsection{Homogenization}

As with the question of whether non-native species reduce biodiversity, the related question of whether or not they tend to homogenize the world's ecosystems is more complex than one might first think. However, as with biodiversity loss, in the final analysis, this concern has merit.

Biotic homogenization occurs when extant ecological assemblages lose their distinctiveness and become more similar. Loss of biological distinctiveness occurs at many levels, including species similarity, similarity of functional relationships, loss of genetic distinctiveness, and similarity of evolutionary history. While there are other causes of biotic homogenization (e.g., when flooding joins what had been two once isolated bodies of water), the human transport of non-native species is a major one.

A key factor in how biotic communities get their distinctiveness is their isolation from one another. When this isolation is overcome, mixing begins, and one gets homogenization. Humans are intentionally and unintentionally transporting species around the globe, overcoming the natural isolation, barriers, and distances that have helped created the spectacular diversity of earth's ecological assemblages. This is a process driven by, and also similar to, the globalization of human economies and cultures. In the human economy, quirky and distinctive "mom and pop" stores on main street are driven out of business by the same big box stores, resulting in towns and cities losing distinctiveness and become more similar. Take a major exit off a U.S. highway interstate and you are likely to find the same two dozen retailers, whether you are in the Pacific Northwest or 3000 miles away in the Southeast. Analogously, the same weedy, generalist species, tolerant of diverse ecological conditions, appear over and over again around the world, often replacing specialist, more sensitive species. These species are ones with "broad diets and tolerances, rapid dispersal 
and high reproduction" (McKinney and Lockwood 1999, 452). "Loser species" are being replace by "winners". 7 Just as McDonald's and Subways has spread all over the world, so have dandelions and rats. Invasion biologist Julian Olden (often one to defend non-native species) says: "From birds to plants to fish to mammals, there's strong evidence that things are becoming more similar" (Goode 2016). A number of studies document that biotic homogenization is occurring, especially in freshwater ecosystems (Petsch 2016). Some even suggest that humans "are creating a new Pangaea by bringing all the world's flora and fauna together" (Kolbert 2017).

Even when non-natives aren't weedy or invasive their presence in new habitats homogenizes by lessening floral and faunal distinctions among regions. Theoretically, non-natives introductions could decrease similarity as when two different fish species are introduced to lakes that otherwise have the same species, or when a nonnative plant colonizes one habitat, but not another which is otherwise identical. But this is an anomaly, if successful non-natives tend to be generalists and widespread.

Consider the phenomenon of zoos (and perhaps also of gardens). Do they increase biodiversity or homogenize? As Holmes Rolston once pointed out, there are more species of animals in the Denver zoo than in all of Colorado. So, in one obvious sense, Denver, in virtue of its zoo, is much less similar to the rest of Colorado. But because of zoos, elephants, for example, are no longer to be found only in African and Asian grasslands and forests, but are now present in any major city on the planet! I think this is a helpful analogy for non-natives in general. While potentially increasing local diversity (until they wipe out native species), they homogenize the world by lessening the distinctiveness of different bioregions and assemblages.

A main rationale for rejecting the notion that non-natives simply homogenize is to emphasize the possibility of hybridization. Just as "the mixing and blending of cultural identities...lead to new forms of diversity" (Keulartz and Van der Weele $2009,244)$ among humans, so too the mixing and blending of species resulting from non-native introduction can lead to new types of biodiversity. In an editorial arguing that the Anthropocene may well increase biodiversity, Thomas argues that "Hybridization is becoming particularly important as formerly separated species are brought into contact. The rates are astounding...Speciation by hybridization is likely to be a signature of the Anthropocene" (Thomas 2013).

But hybridization is a double-edged sword in terms of diversity. "Hybridization has been shown to be a major contemporary extinction force, especially when accompanied by habitat homogenization, causing species declines through introgression, genetic swamping and reproductive interference" (Richardson and Ricciardi 2013, 1463). Similarly, human hybridization can also create loss of diversity and homogenization. Think of the U.S. as a melting pot of peoples, homogenizing them into "Americans." Or what if those Jews who are committed to a distinct Jewish culture

\footnotetext{
${ }^{7}$ Some argue that we should start backing these "winners." "Conservationists must stop spending all their time backing loser species-the endangered and reclusive. They must start backing some winners" (Pearce 2015a, xvi). Of course, we already are, as we are the main cause of their movement to new habitats.
} 
gave up their emphasis on Jews marrying other Jews and fully integrated with other religious cultures. Such "hybridization" would be a loss of a distinctive culture.

\subsection{Naturalness Value and the Antipathy Toward Non-Natives}

We have examined two related reasons for the antipathy toward non-natives: Their negative impact on biodiversity and their tendency to homogenize the world's ecological assemblages. There is another compelling reason for this antipathy: Non-native species seriously exacerbate the continued humanization of earthen nature. Nonnative species, when they are human-introduced, as they are in the vast majority of cases, threaten and diminish a key environmental value, namely, naturalness. Respect for independent nature explains and justifies the antipathy toward non-native species. Human introduction of non-native species is a major way that humans are impacting the natural world. That many, perhaps most, human introductions of non-native species are unintentional does not lessen this point. Naturalness is compromised both by intentional and unintentional human actions.

There are a host of objections to the idea that protecting and restoring naturalness are important environmental obligations. Here I address a few and only in a cursory manner. ${ }^{8}$ Some will argue that humans are natural and so whatever they do is natural, including spreading non-native species all around the globe. But by "natural" I mean the degree to which something is independent of human impact, and clearly spreading species around the globe is a human impact. Others might claim that there is no naturalness left to value or protect, that we are in the "Anthropocene," that anthropogenic climate change and global human pollution are so pervasive that we are (as McKibben claimed years ago) at "the end of nature" and so there is no more naturalness left to defend. But naturalness comes in degrees. Dimensions of nature are more or less impacted by human activities and so defenders of naturalness value urge us to value and protect the naturalness that remains. I have argued that we ought to "value naturalness in the Anthropocene; now more than ever" (Hettinger 2014), as rarity enhances preexisting value and makes it more precious. Those ecosystems which have not been overwhelmed by human-introduced non-natives have a special importance given their relative naturalness. Even ecosystem with significant nonnative presence have remaining naturalness of significant value. ${ }^{9}$ Naturalness can also return over time as humanization washes out of natural systems and humans can themselves speed along such recovery by active "rewilding," as when we remove trash or poisons from natural systems or tear down dams. Restoration of native ecosystems

\footnotetext{
${ }^{8}$ For a somewhat more vigorous defense of the value of naturalness and respect for independent nature, see Hettinger (2018).

${ }^{9}$ Contrast this idea with Keulartz and Van der Weele's (2009) suggestion that the more severely invaded an area is with non-natives, the less reason to worry about their presence.
} 
by removal of human-introduced non-natives often increases the naturalness of those systems.

The connection between non-natives and being unnatural is contingent: what matters for naturalness value is not non-nativeness itself, but the human introduction of non-natives and the loss of naturalness that introduction instantiates. Because the vast majority of non-native species are human-introduced, this disvalue of nonnatives, while not applying to non-natives per se, applies to the vast majority of them. Naturalness value therefore supports the "guilty until proven innocent idea" in a far stronger and secure manner than does the assumption that non-natives are going to cause ecological or other damage. As we have a seen, there is a relatively low probability that non-natives will cause ecological damage (such as species extinction). While the overall negative consequences non-natives have on biodiversity and increasing homogenization seem clear, whether a particular non-native has these effects is not so clear. The case is otherwise concerning the unnaturalness of nonnative species. Because there is a very high probability that a non-native has been human-introduced, rather than being "open minded" about non-natives, naturalness supports a presumption against non-natives. So, the likely unnaturalness of nonnatives counts against the increasingly widespread attitude that each introduction should be evaluated in its own right and in the particular area invaded (Seebens et al. 2017). It provides a compelling response to the many who think it "unclear why our default attitude toward ecological novelty is antagonism or ambivalence" (Thomas 2013). The antipathy toward non-natives results from and is justified by the overwhelming likelihood that they embody the ongoing humanization of nature. The preference for natives over non-natives when they are human introduced is a way of respecting independent nature. The default attitude toward the arrival of a non-native should be negative, until it is proven that it was not human introduced.

I now examine a series of important objections to the preference for natives over non-natives.

\subsection{Is the Antipathy Toward Non-Natives Based on Misleading Popular Ecology?}

The preference for natives over non-natives is a deeply ingrained value for many environmentalists and ordinary people as well. Critics argue that "many introduced populations are considered harmful, not because of their ecological effects per se, but because they challenge deep-seated ideologies about how nature should be" (Wallach et al. 2018, 1263). Ken Thompson, the author of Where do camels belong? Why invasive species aren't all bad, claims "It's almost a religious kind of belief, that things were put where they are by God and that's where they damn well ought to stay" (Goode 2016). I think the nativists can respond, "Guilty as charged": Respect for nature is a "deep-seated ideology" (though an eminently justified one) and that 
the opposition to humans taking over the world and "running nature" is a rejection of the idea that humans should play God with the earth.

It is often claimed that the antipathy toward non-natives is to be based on a set of scientifically dubious ideas which are nonetheless common in popular ecology. The nativists, it is claimed, believe that non-native introductions upset a balance of nature, that ecosystems tend toward an equilibrium that non-natives disrupt, and that change itself is a harm. Nativism based on valuing naturalness can accept that nature is dynamic, adaptive, and in flux, and that there is no one way ecosystems are supposed to be. Their objection is not to change as such, but only human-caused change. Nativism based on natural value favors removal of non-natives, not to prevent "biotic mixing," nor for the purpose of recreating beloved historical assemblages, but to remove or lessen human influence on ecosystems.

\subsection{The Xenophobia Objection}

A longstanding criticism of nativism (whether this be a preference for human or non-human natives) is that it is based on xenophobia, an irrational fear or dislike of the foreign and/or the unfamiliar, perhaps enhanced by feelings of superiority. It is a common (though not laudable) human tendency to identify with a group and to distinguishing group members with whom one feels comfortable from "outsiders" toward whom suspicion is aimed. It is also common to form opinions of others based on hasty generalizations and selectively-constructed stereotypes. When the foreign enters, the fear is of contamination and the desire is to cleanse the home and make it pure again. Critics of nativism believe that these attitudes underlie the antipathy toward non-native "alien" species and that there is a synergy between anti-human immigrant sentiments and the rejection of non-native species.

This criticism is perhaps made more salient in light of recent currents in world politics. A U.S. President argues for "America First," spews forth harsh anti-immigrant rhetoric ("murders, rapists, and drug smugglers are pouring into our country") and advocates policies to prevent and remove the "invaders" (the wall, family separation). These nationalist sentiments and anti-globalization attitudes (e.g., dissolution of the European Union) are not limited to the U.S., nor is the xenophobia which often underlies them. Critics charge that not only nativists in general, but also the field of invasion biologist itself uses biased ("alien species" "exotics") and militarist language ("invasion," "war against exotics") to fuel prejudicial and misleading attitudes and environmental policies toward non-natives.

Clearly there can be synergism between biological and cultural nativism/purism. As it is often pointed out, the Nazis had their own native plant movement purifying the biology of their country at the same time as they purged the human race of its supposed inferior elements. In South Africa, native-plant, gated communities cater to "suburbanites seeking to escape the increasingly mixed and threatening postapartheid city...spaces that exclude problematic plants and people alike" (Ballard and Jones 2011, 1). 
To avoid such a problematic xenophobia, we are urged to accept a cosmopolitan approach toward human immigration and culture and welcome foreigners into our societies. Similarly, we should accept non-native species into our ecosystems, celebrating their rich origins, their geographical and cultural histories, rather than persecuting them because they are not native (Kendle and Rose 2000).

The analogy between human immigration and non-native species introduction is both instructive and potentially misleading. Biological and cultural nativism can be mutually reinforcing, especially when the rhetoric used is similar or identical. This can be true whether or not xenophobic attitudes underlie the rhetoric. Nevertheless, it is important to point out that xenophobia need not underlie either type of nativism.

Consider the biological nativist's antipathy toward non-natives species. Those who prefer native plants in native habitats and eschew the entry of foreign species need not fear or dislike them, nor believe they are inferior. They might think quite highly of these species in their native habitats. For example, I don't want camels to roam the deserts of the southwestern U.S. But I don't fear or hate camels; they are neat animals! And again, I clearly admired that non-native mimosa tree when I planted it in my yard. As we have seen, opposition to non-native species can be based on concerns about harms to biodiversity, worries about homogenization of ecological assemblages, or opposition to the increasing humanization of the world.

It is harder to make the case that cultural nativism need not be based on xenophobia. People who don't want black people, Muslims, or Mexicans in their communities cannot plausibly say I like these folks fine in their own places, I just don't want them here. At least this is true if they are talking about individuals of these groups. However, if we take cultural integrity as a value, then there are non-xenophobic reasons for being concerned about "too much" immigration or "too many foreigners moving in." Mass immigration may threaten distinct and valuable ways of life. The desire to preserve unique cultures, as the desire to preserve unique biological communities, need not be xenophobic and can even be praiseworthy.

For example, the preservation of indigenous cultures is of significant value. Too many natives leaving the community, or too many non-natives entering, threatens this value, as does the ingression of western commercialism. When Southern parents send their children to Southern colleges, when Christian parents send their children to Christian schools, and when Jewish parents lobby their children to marry other Jews, these practices need not (though they obviously can) be based on xenophobic attitudes. Typically, they are based on desires to preserve important cultures or cultural attributes. I now live in a small community in the Rocky Mountain West with some wonderful small-town values: Cars stop for pedestrians, dogs are loved, there is strong community support of children and young women, and the community is extremely supportive of an active outdoor lifestyle. If enough people from large cities who are indifferent or antagonistic to such values moved into town it could destroy a cultural environment of great value. My opposition to the mass movement of such people into town is not xenophobic.

Such opposition to foreign entry is only legitimate when significant cultural values are in jeopardy. The anti-immigrant sentiment in the U.S. is not justified by a serious threat to the national's culture, especially because the U.S. has always 
prided itself a nation of immigrants. The debate about whether this nation of immigrants should promote assimilation (or homogenization!) for the sake of a unified culture or embrace a multi-cultural society is in some ways similar to debates about the importance of retaining unique biological communities in light of the concerns about homogenization.

These are complicated issues, but it should be clear from this discussion that biological nativists antipathy to non-natives cannot be summarily dismissed by accusations of xenophobia or contribution to xenophobia.

\subsection{The Need for Non-Natives in the Anthropocene}

A particularly provocative challenge to nativism is the idea that non-native species are increasingly essential to human and planetary flourishing. That they always have been becomes obvious if we focus on the human food supply. Pimentel et al. (2005) claims that "Introduced species, such as corn, wheat, rice, and other food crops, and cattle, poultry, and other livestock, now provide more than $98 \%$ of the U.S. food system." A more recent study suggested that worldwide an average of $70 \%$ of food crops were introduced from other regions (Khoury et al. 2016). But the critics are insisting on the importance of non-natives far beyond the agricultural domain so important to humans. It is alleged that wild nature needs them too, as indicated in the title of this recent book by Fred Pearce: The new wild: Why invasive species will be nature's salvation. Pearce writes:

The more damage that humans do to nature - through climate change, pollution, and grabbing land for intensive agriculture and plantation forestry-the more important alien species and novel ecosystems will be to ensuring nature's survival. Aliens are rapidly changing from being part of the problem to part of the solution. (Pearce 2015a, 178)

Emma Marris makes a similar claim in her book Rambunctious garden: Saving nature in a post-wild world:

As the planet warms and adapts to human domination, it is the exotic species of the world that are busy moving, evolving, and forming new ecological relationships. The despised invaders of today may well be the keystone species of the future's ecosystems, if we give them the space to adapt and don't rush in and tear them out. (Marris 2011, 109)

Even sober biologists think that:

Non-native species might contribute to achieving conservation goals in the future because they may be more likely than native species to persist and provide ecosystem services in areas where climate and land use are changing rapidly and because they may evolve into new and endemic taxa. (Schlaepfer et al. 2011, 428)

We have seen that non-native species can and do contribute to biodiversity, although in ambiguous and ambivalent ways. They provide "ecosystem services" as when nonnative sea grass provides a nursery and regulates water flow in places that have lost their native habitat formers. Other ecosystem services non-natives provide include 
food, pollination, water purification, seed dispersal, and the list goes on. Obviously, non-native species are biological creatures that can serve most all the biological functions that native species do. In a harsher and more unstable environment, they will more likely persist as they tend to be generalists rather than specialists and also better competitors. By refusing to accept non-natives species as legitimate parts of nature, the critics argue, people are blinded to these sorts of beneficial roles they can play (Wallach et al. 2018).

I believe there is room in the conservation agenda for both a focus on preserving and restoring native biodiversity, and occasional, though increasing, acceptance of non-natives in the specific cases when they provide sufficient benefits.

I agree with Marris that we must go beyond "black and white thinking on nonnative species" (Marris 2014, 516). It is matter of weighing costs and benefits. It is important while highlighting the potential benefits of non-natives to remember how damaging non-native species can be. A few years ago, there was a report suggesting that "the annual combined economic cost of invasions worldwide exceeds that of natural disasters" and the authors argued that we should prepare for non-native species invasion in ways similar to how we prepare for (other?) natural disasters (Ricciardi et al. 2011). Perhaps this is hyperbole, but we should remember that the disasters perpetuated by non-native species are for the most part not "natural," but self-inflicted, as humans move these species around the globe. In cases where non-natives provide the sort of ecosystem services described above, we must weigh these biological benefits against the potential biological costs, both in terms of loss of biodiversity and homogenization. Even when this calculus turns out positive, we must compare these benefits to the loss of naturalness value that the human-introduced of nonnatives involves. This is a classic case of conflict between two important conservation values, biodiversity and naturalness. I think despite the multi-faceted ways non-native species can be beneficial, non-natives bring with them sufficient probable disvalue to justify the generalized antipathy toward them and legitimizes the policy of treating them as guilty until proven innocent. The burden very much has to be on the defender of non-natives to prove they are not simply benign, but beneficial overall.

\subsection{Non-Native Animals in Our Midst}

In this last section I explore two related issues. First, how the conception of nonnative species applies to animals, particularly "animals in our midst." Secondly, what sort of implications for our treatment of animals follows from the issues raised by the native/non-native species controversy?

As background, it should be noted (with outrage) that there has been, on average, a $60 \%$ decline in populations of vertebrate animals worldwide in last 40 years. ${ }^{10}$

\footnotetext{
${ }^{10}$ This does not mean a $60 \%$ decline in number of individual vertebrate animals on the planet because the sizes of the populations studied varies dramatically. For an explanation, see Brown (2018).
} 
My focus will be on sentient animals (which I believe are roughly co-extensive with vertebrates) as it is with this (relatively small) subset of animals that especially powerful moral considerations arise and with them questions of treatment diverge in comparison to plants (and non-sentient animals).

How to conceptualize urban and rural animals, or wild animals, that wander or are thrust into human habitats is important in part because this phenomenon is increasing dramatically. Humans continue to encroach on animal habitats, and in response, they come into ours. For many, such as rats, coyotes, and song birds, human habitats are particularly compelling, providing food, shelter, and protection from predators. Such animals also raise interesting questions for the distinction between natives and non-natives.

The understanding of native species embraced herein is that native species are those that have significantly adapted/interacted with the local biota and abiota. Nonnatives are those have not done so. Being native is a matter of degree and non-natives can naturalize over time. Applied to "animals in our midst," this suggest that new arrivals from habitats totally unlike the habitats they now inhabit should be conceived as non-native. So the "Golden-headed lion tamarins, squirrel sized monkeys," that "came out of the disappearing coastal forests of Brazil and found a new home in the suburbs of Rio de Janeiro" (Pearce 2015b) are not native to those suburbs. In contrast, squirrels who have lived in Rio for generations are native to the city as they have adapted/interacted with the flora and fauna (including humans) and abiota (houses, streets, soil) for quite some time. And the locals (including humans) have adapted/interacted with them. (For example, humans have developed and deployed squirrel-proof, bird feeders.) Further, squirrels brought into Rio de Janeiro from other cities would be more native than the monkeys, for they have adapted/interacted with humans and human abiotic environments more so than have the monkeys (although they might not have adapted to the particular species of flora and fauna in Rio). Or considers the house sparrow. Although European in origin, it has adapted to humans and human habitats world-wide and, on the conception developed here, should be considered a native species of these urban and suburban habitats. Coyotes in American suburbs and cities (one was seen stalking a fast-food restaurant in Chicago!) are an interesting case. Though once widespread in America, they are just recently returning to much of their former habitat and they and the locals (including humans) are just beginning the mutual adaptation/interaction that will revive their nativity.

Paul Knights has suggested a "cultural criterion" for being native to human communities, arguing that cultural relationships humans have with species helps ground their nativity (Knights 2008). The type of cultural relationships and associations he has in mind include having common names for the species (Jack in the Pulpit), being used in play (buttercup under chin, bracelets made from daisies, kisses under mistletoe), being adopted in local cuisine (berries turned into jam, fish for dinner), being used for medicinal purposes, being used as a source for literary or artistic expression, and so on. Although Knights distinguishes these cultural relationships from ecological relationships, for the most part these cultural relationships have an ecological character to them. Part of the criterion for nativeness I have 
proposed includes human adaptation/interaction to the species in these human habitats. Thus, these cultural relationships add to nativity, at least in so far as they involve an ecological component. If these cultural associations between species in human habitats and humans involves interaction/adaptation (which for the most part they do), then such associations do add to native characterization. When a species in a human environment is ignored by humans, this means there is less interaction and thus a diminished claim to being native.

Human treatment of animals in general is harsh, but peculiarly harsh toward animals perceived as non-native or animals considered to be invasive. Examples include, laser censors that spray poison on wildcats and viral diseases used to infect wild rabbits (Wallach et al. 2018). Sometimes species are labeled non-native as a way to help justify getting rid of them. English farmers have objected to beaver restoration on these grounds and coyotes are often tarred with the label non-native at the same time they are being persecuted. Mountain goats judged as not native to many U.S. National Parks are accused of "invading" the parks rather than simply beginning to colonize them. Do the 200 goats that live "in and adjacent to" Yellowstone National Park constitute an "invasion?" Yes, their presence is due to humans, their waste changes the soil chemistry in some sites, and they may compete with native bighorn sheep (and pass on disease to them). But is it really true that "This non-native species poses a threat to Yellowstone's alpine as well as bighorn sheep" (Yellowstone National Park 2019)? Perhaps. And perhaps they should be removed. But the non-native species invasion language inclines the discussion toward this outcome.

I have argued in favor of antipathy toward non-native species, including the "guilty until proven innocent" attitude. But sentient animals have a special value that other species lack. Because of this, I think the antipathy toward non-natives should be relaxed for sentient animal species and policies based on guilt unless proven innocent should be suspended. What justifies this differential treatment is that sentient animals-unlike insentient animals and plants-have feeling and desires. Their lives can go well or badly from their own perspective and they can suffer horribly. Because of these capacities, we should treat them as individuals and as having certain rights. Most clearly, they have the right not to have suffering inflicted on them, unless sufficiently strong justification for that suffering is presented, including the ruling out of less painful alternatives. ${ }^{11}$ Perhaps sentient animals should even be given the presumption of freedom of movement.

Recall that what justifies the presumption of guilt against non-natives is that the vast majority of non-native species are human-introduced and such introduction decreases naturalness, something I have argued is an especially important value in our time of massive and ongoing humanization of earth. Concerns about loss of biodiversity and homogenization are also important, but cannot be simply assumed in the case of non-natives. Instead, they require investigation. But with sentient animals another definitive value is added to the mix. We should not shoot non-native mountain

\footnotetext{
${ }^{11}$ For example, if gene drives can be used to sterilize populations of invasive sentient animals threatening extinction of native species, they should be seriously considered as an alternative to traditional mechanisms (such as poison) that involve great suffering.
} 
goats who stray into our national parks simply on grounds that it is exceeding likely they are human-introduced. I do not think the loss of naturalness value this (likely) represents is by itself sufficient to justify immediate dispatch. Their unnaturalness will count in favor of their removal, as will their possible effects on biodiversity and homogenization. But the burden of proof will have shifted because these species have a special value. ${ }^{12}$ Note that with non-native plants or insentient animals (e.g., insects) the presumption of guilt remains and their expedited removal is permissible, for they lack the burden shifting value that comes with the rights of sentient animals.

\subsection{Conclusion}

This essay has defended biological nativism and its antipathy toward non-natives. Native species are those that have significantly adapted/interacted with local biota and abiota. Non-natives are increasingly pervasive, their presence indicative of and caused by massively increasing human global impact. While climate change puts pressure on the distinction, the categories of native and non-native remain relevant and important in environmental thought. There are serious concerns about and evidence supporting non-natives' negative impacts on biodiversity and their homogenization of ecosystems. However, there are numerous instances where non-natives contribute positively to biodiversity and such contributions are likely to increase. Nonetheless, the generalized antipathy toward non-natives is justified by respect for independent nature, as the vast majority of non-natives are introduced by humans and thus are part of the ever increasing and arrogant human domination of once natural dimensions of earth. Preference for natives need not be based on prejudicial dislike of the foreign or misconceived ideas about natural systems. Animals can become native to human habitats and the special value of sentient animals suggest that, for them alone, we should withhold our presumption in favor of expedited removal of non-native species. The preference for native species over non-natives continues to be a significant environmental value and one that is rationally defensible.

\section{References}

Ballard, R., and G. Jones. 2011. Natural neighbors: Indigenous landscapes and eco-estates in Durban, South Africa. Annals of the Association of American Geographers 101 (1): 131-148.

Bellard, C., P. Cassey, and T. Blackburn. 2016. Alien species as a driver of recent extinctions. Biology Letters 12 (2). https://royalsocietypublishing.org/doi/full/10.1098/rsbl.2015.0623.

Brown, E. 2018. Widely misinterpreted report still shows catastrophic animal decline. National Geographic, November 1.

\footnotetext{
${ }^{12}$ That the burden has shifted does not mean that non-native sentient animals should be allowed to wreak havoc on native species. Severely negative impacts on biodiversity (e.g., causing species extinction) clearly can justify killing and even causing suffering to sentient animals.
} 
Chew, M. 2015. Ecologists, environmentalists, experts, and the invasion of the 'Second Greatest Threat'. In International review of environmental history, vol. 1, ed. J. Beattie, 7-40. Canberra: Australian National University Press.

Chew, M., and A. Hamilton. 2011. The rise and fall of biotic nativeness: A historical perspective. In Fifty years of invasion ecology: The legacy of Charles Elton, ed. D. Richardson, 36-47. Chichester, UK: Blackwell Publishing.

Crawford, A. 2018. Why we should rethink how we talk about 'alien' species. Smithsonian Magazine, January 9. https://www.smithsonianmag.com/science-nature/why-scientists-are-starting-ret hink-how-they-talk-about-alien-species-180967761. Accessed 23 March 2020.

Davis, M., and M. Chew. 2017. 'The denialists are coming!' Well, not exactly: A response to Russell and Blackburn. Trends in Ecology \& Evolution 32 (4): 229-230.

Davis, M., M. Chew, R. Hobbes, A. Lugo, J. Ewel, G. Vermeij, et al. 2011. Don't judge species by their origin. Nature 474: 153-154.

Fox, D. 2007. Back to the no-analog future? Science 316 (5826): 823-825.

Goode, E. 2016. Invasive species aren't always unwanted. New York Times, February 29. https:// www.nytimes.com/2016/03/01/science/invasive-species.html.

Hettinger, N. 2001. Exotic species, naturalization, and biological nativism. Environmental Values 10 (2): 193-224.

Hettinger, N. 2014. Valuing naturalness in the Anthropocene: Now more than ever. In Keeping the wild: Against the domestication of earth, ed. G. Wuerthner, E. Crist, and T. Butler, 174-179. Washington, DC: Island Press.

Hettinger, N. 2018. Naturalness, wild-animal suffering, and Palmer on laissez-faire. Les Ateliers de l'éthique 13 (1): 65-84. https://www.erudit.org/fr/revues/ateliers/2018-v13-n1-ateliers04192/ 1055118ar.pdf.

Justus, J. 2009. Exotic species. In Encyclopedia of environmental ethics and philosophy, ed. J.B. Callicott and R. Frodeman, 412-414. Macmillan Reference USA.

Kendle, A., and J. Rose. 2000. The aliens have landed! what are the justifications for 'native only' policies in landscape plantings?. Landscape and Urban Planning 47 (1): 19-31.

Keulartz, J., and C. van der Weele. 2009. Between nativism and cosmopolitanism: Framing and reframing in invasion biology. In New visions of nature, ed. M. Drenthen, J. Keulartz, and J. Proctor, 237-256. Dordrecht, The Netherlands: Springer.

Khoury, C., H. Achicanoy, A. Bjorkman, C. Navarro-Racines, L. Guarino, and X. Flores-Palacios. 2016. Origins of food crops connect countries worldwide. Proceedings of the Royal Society B: Biological Sciences 283: 20160792. http://dx.doi.org/10.1098/rspb.2016.0792.

Knights, P. 2008. Native species, human communities and cultural relationships. Environmental Values 17 (3): 353-373.

Kolbert, E. 2014. The sixth extinction: An unnatural history. New York: Henry Holt.

Kolbert, E. 2017. The fate of the earth. The New Yorker, October 12. https://www.newyorker.com/ tech/annals-of-technology/the-fate-of-earth.

Lodge, D., and K. Shrader-Frechette. 2003. Nonindigenous species: Ecological explanation, environmental ethics, and public policy. Conservation Biology 17 (1): 31-37.

Lundgren, E.J., D. Ramp, W.J. Ripple, and A.D. Wallach. 2018. Introduced megafauna are rewilding the Anthropocene. Ecography 41: 857-866.

Marris, E. 2011. Rambunctious garden: Saving nature in a post-wild world. New York: Bloomsbury.

Marris, E. 2014. 'New conservation' is an expansion of approaches, not an ethical orientation. Animal Conservation 17 (6): 516-517.

McKinney, M., and J. Lockwood. 1999. Biotic homogenization: A few winners replacing many losers in the next mass extinction. Trends in Ecology \& Evolution 4 (11): 450-453.

Palmer, C. 2016. Saving species but losing wildness: Should we genetically adapt wild animal species to help them respond to climate change? Midwest Studies in Philosophy 40 (1): 234-251.

Paolucci, M., H. MacIsaac, and A. Ricciardi. 2013. Origin matters: Alien consumers inflict greater damage on prey populations than do native consumers. Diversity and Distributions 19 (8): 988995. 
Pauchard, A, L.A. Meyerson, S. Bacher, T.M. Blackburn, G. Brundu, M.W. Cadotte et al. 2018. Biodiversity assessments: Origin matters. PLoS Biol 16 (11): e2006686. https://doi.org/10.1371/ journal.pbio.2006686.

Pearce, F. 2015a. The new wild: Why invasive species will be nature's salvation. Boston: Beacon Press.

Pearce, F. 2015b. Invasive species will save us: The new way we must think about the environment now. Salon, April 11. https://www.salon.com/2015/04/11/invasive_species_will_save_us_the_ new_way_we_must_think_about_the_environment_now/. Accessed 23 March 2020.

Petsch, D. 2016. Causes and consequences of biotic homogenization in freshwater ecosystems. International Review of Hydrobiology 101 (3-4): 113-122.

Pimentel, D., R. Zuniga, and D. Morrison. 2005. Update on the environmental and economic costs associated with alien-invasive species in the United States. Ecological Economics 52 (3): 273-288.

Pysek, P. 1998. Alien and native species in Central European urban floras: A quantitative comparison. Journal of Biogeography 25 (1): 155-163.

Ricciardi, A., M. Palmer, and N. Yan. 2011. Should biological invasions be managed as natural disasters? BioScience 61 (4): 312-317.

Richardson, D., and A. Ricciardi. 2013. Misleading criticisms of invasion science: A field guide. Diversity and Distributions 19: 1461-1467.

Russell, J., and T. Blackburn. 2017. The rise of invasive species denialism. Trends in Ecology \& Evolution 32 (1): 3-6.

Sagoff, M. 2000. Why exotic species are not as bad as we fear. Chronicle of Higher Education 46 (42): B7.

Sax, D., S. Gaines, and J. Brown. 2002. Species invasions exceed extinctions on islands worldwide: A comparative study of plants and birds. The American Naturalist 160 (6): 766-783.

Schlaepfer, M. 2018. Do non-native species contribute to biodiversity? PLoS Biol 16 (4): e2005568. https://journals.plos.org/plosbiology/article?id=10.1371/journal.pbio.2005568.

Schlaepfer, M., D. Sax, and J. Olden. 2011. The potential conservation value of non-native species. Conservation Biology 25 (3): 428-437.

Seebens, H., T. Blackburn, E. Dyer, P. Genovesi, P. Hulme, and J. Jeschke. 2017. No saturation in the accumulation of alien species worldwide. Nature Communications 8: 14435. https://doi.org/ 10.1371/journal.pbio.2005568.

Simberloff, D., L. Souza, M. Nuñez, M. Barrios-Garcia, and A. Windy. 2012. The natives are restless, but not often and mostly when disturbed. Ecology 93 (3): 598-607.

Slezak, M. 2015. Cane toad has surprise effect on Australian ecosystem. New Scientist, March 19. https://www.newscientist.com/article/dn27199-cane-toad-has-surprise-effect-on-australianecosystem/.

Switzer, D., and N. Angeli. 2016. Human and non-human migration: Understanding species introduction and translocation through migration ethics. Environmental Values 25: 443-463.

Theodoropoulos, D.I. 2003. Invasion biology: Critique of a pseudoscience. Blythe, CA: Avvar Books.

Thomas, C. 2013. The Anthropocene could raise biological diversity. Nature 502 (7469): 7.

Thompson, K. 2014. Where do camels belong? Why invasive species aren't all bad. Vancouver, BC, Canada: Greystone Books.

Verburg, G. 2007. Policy memorandum on invasive exotic species. Letter by minister Verburg (LNV) describing the intentions for policy on invasive exotic species. https://www.government. nl/topics/environment/documents/parliamentary-documents/2009/10/15/policy-memorandumon-invasive-exotic-species.

Wallach, A., A. Bekoff, C. Batavia, M. Nelson, and D. Ramp. 2018. Summoning compassion to address the challenges of conservation. Conservation Biology 32 (6): 1255-1265.

Woods, M., and P. Moriarty. 2001. Strangers in a strange land: The problem of exotic species. Environmental Values 10 (2): 163-191.

World Wildlife Fund (WWF). 2014. Living planet report. https://www.worldwildlife.org/pages/liv ing-planet-report-2014. 
World Wildlife Fund (WWF). 2018. Living planet report. https://www.worldwildlife.org/pages/liv ing-planet-report-2018.

Yellowstone National Park. 2019. Mountain Goat. https://www.nps.gov/yell/learn/nature/mountaingoat.htm. Accessed 23 March 2020.

Ned Hettinger is Professor Emeritus of Philosophy at the College of Charleston. His specialization is environmental philosophy, including environmental ethics, environmental aesthetics, and animal ethics. His papers have been published in Philosophy and Public Affairs, Boston College Environmental Affairs Law Review, Environmental Ethics, Environmental Values, and the Journal of Aesthetic Education among other places. Recent articles include "Naturalness, Wild-Animal Suffering, and Palmer on Laissez-faire" (2018) and "Evaluating Positive Aesthetics" (2017). His homepage is: http://hettingern.people.cofc.edu.

Open Access This chapter is licensed under the terms of the Creative Commons Attribution 4.0 International License (http://creativecommons.org/licenses/by/4.0/), which permits use, sharing, adaptation, distribution and reproduction in any medium or format, as long as you give appropriate credit to the original author(s) and the source, provide a link to the Creative Commons license and indicate if changes were made.

The images or other third party material in this chapter are included in the chapter's Creative Commons license, unless indicated otherwise in a credit line to the material. If material is not included in the chapter's Creative Commons license and your intended use is not permitted by statutory regulation or exceeds the permitted use, you will need to obtain permission directly from the copyright holder.

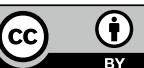

